\title{
STRATEGI PERGURUAN TINGGI DALAM MENINGKATKAN PUBLIKASI HASIL PENELITIAN
}

\author{
Hamdan Sugilar ${ }^{1}$, Tedi Priatna ${ }^{2}$, Wahyudin Darmalaksana ${ }^{3}$ \\ ${ }^{1}$ Prodi Pendidikan Matematika UIN Sunan Gunung Djati, JL. AH. Nasution 105, Bandung, Indonesia, \\ ${ }^{2}$ Prodi Pendidikan Agama Islam UIN Sunan Gunung Djati, JL. AH. Nasution 105, Bandung, Indonesia, \\ ${ }^{3}$ Prodi Tafsir Hadits UIN Sunan Gunung Djati, JL. AH Nasution 105, Bandung, Indonesia \\ ahamdansugilar@uinsgd.ac.id
}

\begin{abstract}
Research without the publication has not provided meaning about benefits and research results. Research results need to be published or disseminated to benefit the community. The purpose of this study is to determine the strategy of universities in the acceleration of publication of research results. The research method used a qualitative approach. Sources of data consist of interviews with lecturers and team of journal publications, document studies, and reports on the achievements of publications of scientific papers. This study uses inductive thinking. This research was conducted on journal team and publication of Universitas Pendidikan Indonesia and research and publishing institute of UIN Sunan Gunung Djati Bandung. Based on the research obtained the following results: Universities make strategic plans and master plan research in achieving publication of research results; to form journal team and publication and term of reference (TOR) publication of research result
\end{abstract}

Keywords: Strategy, Principals, Accreditation

\section{PENDAHULAN}

Perguruan Tinggi terus berupaya untuk meningkatkan jumlah publikasi karya ilmiah dosen dalam bentuk jurnal Internasional. Regulasi yang dikeluarkan pemerintah mengatur dan mendorong setiap perguruan tinggi untuk memberikan kontribusi dalam pencapaian publikasi jurnal internasional dan mendongkrak jumlah capaian publikasi yang naik secara signifikan. UndangUndang Nomor 12 Tahun 2012 tentang Pendidikan Tinggi yang mengamanatkan alokasi 30\% dari dana Bantuan Operasional Pendidikan Tinggi Negeri menegaskan bahwa penelitian adalah bagian penting dalam perguruan tinggi. Hal tersebut harus direspon dengan baik melalui action nyata para civitas akademika untuk giat meneliti, menulis dan publikasi.

Publikasi ilmiah pada jurnal internasional bereputasi masih didominasi pada bidang science dan engineering. Perlu didorong para peneliti di bidang non-science untuk publikasi ilmiah. Upaya meletakkan "Scientific Work" di Perguruan Tinggi masih minim. Scientific work misalnya: berdiskusi di laboratorium, menulis bersama. Hasil publikasi dari tulisan ilmiah adalah momen besar yang berhubungan erat dengan kebanggaan suatu Negara, dan sebagai 
penghubung antara peneliti dan masyarakat pengguna (Sunarno, 2009). Banyaknya karya ilmiah yang dimiliki oleh suatu Negara berdampak pada semakin dihormatinya bangsa tersebut dalam hal keilmiahan (Asep Bayu Dani Nandiyanto, 2016).

Pemerintah melalui kementerian riset dan teknologi perguruan tinggi dan perguruan tinggi Islam terus berupaya mendorong dosen untuk melakukan penelitian yang bernilai jual serta bermutu dan berkualitas. Hasil penelitian tersebut kemudian didesiminasikan atau dipublikasikan kepada jurnal bereputasi nasional atau bereputasi internasional, tentu ini menjadi nilai jual dan menaikkan reputasi dosen. Semakin banyak hasil penelitian yang terpublikasi akan meningkatkan jumlah citasi jurnal atau paper tersebut. Untuk mencapai sasaran target tersebut masingmasing perguruan tinggi berupaya keras untuk meningkatkan jumlah publikasi hasil penelitian karena ini akan berdampak pada peringkat perguruan tinggi (PT) pada data base SINTA (Science and Technology Index)

\section{METODE PENEUTIAN}

Penelitian ini menggunakan pendekatan atau metode kualitatif. Subjek penelitian ini adalah tim jurnal dan publikasi Universitas Pendidikan Indonesia (UPI) dan UIN Sunan Gunung Djati Bandung. Jumlah subjek penelitian 64 orang terdiri dari: tim jurnal dan publikasi UPI, tim TOT, kelas menulis dan dosen. Untuk mendapatkan informasi perihal publikasi hasil penelitian, peneliti memberikan angket, wawancara, dan studi dokumentasi.

\section{HASIL PENEUTANDANPEMBAHASAN}

Pusat Penelitian dan Penerbitan LP2M UIN Sunan Gunung Djati Bandung mempunyai peran yang sangat strategis sebagai leading sector dalam pelaksanaan kegiatan penelitan. LP2M sendiri mempunyai tugas melaksanakan, mengoordinasikan, memantau dan menilai kegiatan penelitian dan pengabdian kepada masyarakat berdasarkan kebijakan Rektor (Rencana Induk Penelitian UIN Sunan Gunung Djati, 2015).

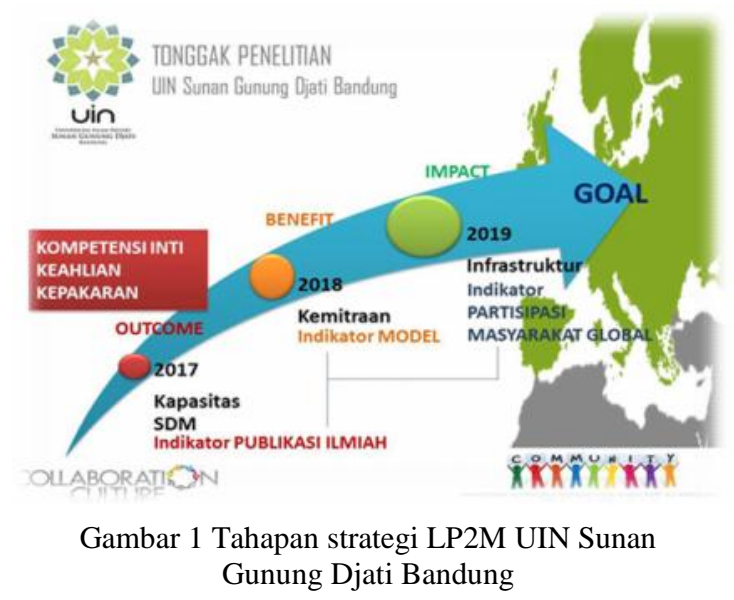

Pusat penelitian dan penerbitan (Puslitpen) UIN Sunan Gunung Djati Bandung terus berupaya dan "berlari" untuk mendorong dosen agar mampu dan terbiasa untuk menulis dan mempublikasikan hasil penelitiannya. Kegiatan penelitian merupakan bagian dari tridarma perguruan tinggi yang tentunya dosen terbiasa dalam hal ini, namun masih sedikitnya jumlah hasil publikasi hasil penelitian dan pendaftaran hak kekayaan intelektual tentunya akan mengurangi jumlah karya tulis dosen berupa hasil penelitian berdasarkan ranking publikasi. Berikut disajikan peringkat hasil publikasi pada SINTA di lingkungan PTKIN. 
Tabel 3 Peringkat 5 Besar Publikasi Ilmiah Berdasarkan SINTA di Lingkungan PTKIN

\begin{tabular}{|c|c|c|}
\hline Perguruan Tinggi & $\begin{array}{c}\text { Peringkat } \\
\text { Nasional }\end{array}$ & Skor \\
\hline UIN Syarif Hidayatullah & 28 & 1.447 \\
\hline $\begin{array}{c}\text { UIN Sunan Gunung Djati } \\
\text { Bandung }\end{array}$ & 31 & 1.347 \\
\hline $\begin{array}{c}\text { UIN Sunan Kalijaga } \\
\text { Yogyakarta }\end{array}$ & 69 & 359 \\
\hline UIN Walisongo & 115 & 124 \\
\hline STAIN Kudus & 136 & 86 \\
\hline
\end{tabular}

\section{Data Publikasi Jurnal Bereputasi Internasional (Scopus)}

Salah satu outcome hasil penelitian adalah publikasi hasil penelitian pada jurnal bereputasi internasional yaitu scopus. Scopus merupakan pengindeks jurnal internasional bereputasi yang memiliki data base hasil penelitian yang lengkap dengan data jurnal yang banyak melalui proses review yang sangat ketat dilengkapi dengan data jurnal yang menunjukkan tingkat pengaruh suatu jurnal (journal impact) atau institusi (institutional impact) dalam dunia publikasi ilmiah.

Tabel 2. Data Publikasi Jurnal Internasional Terindeks Scopus

\begin{tabular}{|c|c|c|c|c|c|c|}
\hline \multirow[t]{2}{*}{ Institusi } & \multirow[t]{2}{*}{ Dokumen } & \multicolumn{4}{|c|}{ Tahun } & \multirow{2}{*}{$\begin{array}{l}\text { Total } \\
\text { Seluruh } \\
\text { Data }\end{array}$} \\
\hline & & 2014 & 2015 & 2016 & 2017 & \\
\hline UPI & Scopus & 37 & 32 & 116 & 101 & 387 \\
\hline $\begin{array}{l}\text { UIN SGD } \\
\text { Bandung }\end{array}$ & Scopus & 10 & 12 & 26 & 27 & 108 \\
\hline
\end{tabular}

Sumber

http:// sinta2.ristekdikti.go.id/affiliations/detail?id $=414 \& v$ iew=overview dan dokumen puslitpen UIN Sunan Gunung Djati (tanggal 13 September 2017)

Berdasarkan tabel 2 di UPI dari tahun 2015 ke tahun 2016 terjadi peningkatan atau percepatan publikasi hasil penelitian pada jurnal terindeks scopus sebesar 362,5\% dari jumlah dokumen 32 pada tahun 2015 menjadi 116 dokumen pada tahun 2016.
Hal ini disebabkan UPI focus pada output hasil penelitian dengan membentuk tim pengembang jurnal dan publikasi. Tim ini focus pada upaya mempublikasikan hasil penelitian dosen pada jurnal bereputasi internasional terindeks scopus. Alasan pemicunya karena UPI berstatus sebagai PT Berbadan Hukum harus "berlari" untuk meningkatkan publikasi internasionalnya.

Upaya lain yang ditempuh oleh UPI adalah dengan menyelenggarakan konferensi internasional. Konferensi tersebut bermaksud untuk memfasilitasi dosen UPI sendiri dan dari luar UPI untuk memudahkan publikasi pada jurnal bereputasi internasional terindeks scopus.

Kegiatan konferensi dalam rangka mengumpulkan artikel agar dapat terpublikasi pada pengindeks scopus. Adapun tahapan kegiatan konferensi sebaga berikut: menentukan tema dan template konferensi, mengadakan kontak dengan publisher yang terindeks scopus untuk membuat Mou kerjasama supaya artikel yang terjaring pada kegiatan konferensi dapat lolos untuk dipublish melalui rangkaian ketat revisi oleh reviewer yang ahli sesuai kapsitasnya.

\section{Respon dan Tanggapan Dosen terhadap Publikasi}

Berdasarkan hasil angket yang disebarkan kepada tim pengembang dan publikasi jurnal, Academic Writing atau dosen UPI dan UIN SGD diperoleh kembali lembar hasil angket sejumlah 64 dosen. Berikut disajikan hasil angket pada tabel 3 berikut:

Tabel 3 Tanggapan Dosen terhadap Publikasi Hasil Penelitian

\begin{tabular}{|l|lr|l|l|}
\hline No & Pernyataan & Ya (\%) & Tidak (\%) \\
\hline 1. & $\begin{array}{l}\text { Saya memiliki } \\
\text { jurnal/prosiding } \\
\text { internasional }>3 \text { paper }\end{array}$ & $\begin{array}{r}\text { publikasi } \\
\text { bereputasi }\end{array}$ & & \\
\hline
\end{tabular}




\begin{tabular}{|c|c|c|}
\hline 2. & 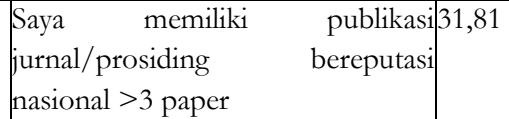 & 68,19 \\
\hline 3. & \begin{tabular}{|l}
$\begin{array}{l}\text { Saya memiliki kesulitan dalam } \\
\text { menulis jurnal }\end{array}$ \\
\end{tabular} & 32,81 \\
\hline 4. & $\begin{array}{l}\text { Saya memiliki kesulitan dalam } 64,69 \\
\text { mengikuti konferensi nasional atau } \\
\text { internasional }\end{array}$ & 35,31 \\
\hline 5. & $\mid \begin{array}{l}\text { Saya mengalami kesulitan dalam } \\
\text { mempublish jurnal pada jurnal } \\
\text { bereputasi nasional }\end{array}$ & 38,10 \\
\hline 6. & $\begin{array}{l}\text { Saya mengalami kesulitan dalam } 75,00 \\
\text { mempublish jurnal pada jurnal } \\
\text { bereputasi internasional }\end{array}$ & 25,00 \\
\hline 7. & $\begin{array}{l}\text { Perguruan tinggi memfasilitasi } 60,94 \\
\text { teknik penulisan pada jurnal }\end{array}$ & 39,06 \\
\hline 8. & $\begin{array}{l}\text { Perguruan tinggi mendanai } 64,06 \\
\text { kegiatan publikasi jurnal/prosiding }\end{array}$ & 35,94 \\
\hline 9. & $\begin{array}{l}\text { Saya akan mempublikasi hasil } 65,63 \\
\text { penelitian walau tidak ada bantuan } \\
\text { dari perguruan tinggi }\end{array}$ & 34,37 \\
\hline 10. & $\begin{array}{l}\text { Regulasi yang mewajibkan dosen } 56,25 \\
\text { untuk mempublikasikan hasil } \\
\text { penelitian membebani dosen }\end{array}$ & 43,75 \\
\hline
\end{tabular}

Tabel 3. Respon Dosen Terhadap Publikasi Hasil Penelitian

Berdasarkan tabel tersebut 25\% dosen memiliki publikasi jurnal/prosiding bereputasi internasional $>3$ paper, hasil ini sebagian masalahaknuya dikarenakan 75\% dosen mengalami kesulitan dalam mempublish jurnal pada jurnal bereputasi internasional dan 64,69\% dosen memiliki kesulitan dalam mengikuti konferensi nasional atau internasional. Data tersebut diperkuat dengan hasil wawancara pada beberapa dosen faktor penyebabnya dikarenakan tidak memahami template dan scope jurnal, tidak memiliki dana yang cukup untuk publish, kesulitan dalam bahasa inggris dan kesulitan pula dalam menyajikan tulisan ke bentuk jurnal sehingga sering kali artikel langsung di reject.

PT melakukan kebijakan melalui bantuan subsidi publikasi hasil penelitian pada jurnal/prosiding bereputasi internasional, $60,94 \%$ dosen berpendapat bahwa perguruan tinggi memfasilitasi teknik penulisan pada jurnal dan 64, 06\% dosen berpendapat bahwa perguruan tinggi mendanai kegiatan publikasi jurnal/prosiding melalui subsidi atau bantuan mengikuti kegiatan conference.

Publikasi hasil penelitian merupakan kewajiban dosen yang telah diatur Peraturan Menteri Riset Teknologi dan Pendidikan Tinggi Nomor 20 tahun 2017 tentang Tunjangan Profesi Dosen dan Tunjangan Kehormatan Profesor mewajibkan dosen yang memiliki jabatan akademik Lektor Kepala dan Profesor untuk melakukan publikasi ilmiah dan Peraturan Menteri Pemberdayaan Aparatur Negara dan Reformasi Birokrasi (Permen PAN-RB) Nomor 17 Tahun 2013 bahwa publikasi ilmiah di jenjang nasional maupun internasional harus menjadi suatu kebutuhan yang tidak terpisahkan dari kegiatan Tri Dharma Perguruan Tinggi (Lukman, Dkk. 2016).

$65,63 \%$ dosen akan mempublikasi hasil penelitian walau tidak ada bantuan dari perguruan tinggi hal ini berarti ada upaya dan itikad dari dosen untuk melakukan publikasi hasil penelitian dan $43,75 \%$ dosen berpendapat bahwa regulasi yang mewajibkan dosen untuk mempublikasikan hasil penelitian tidak membebani dosen.

Pertanyaan terbuka melalui angket yang diberikan kepada responden disimpulkan sebagai berikut: Apa yang bapak/ibu akan lakukan untuk meningkatkan jumlah publikasi hasil penelitian? : Berkolaborasi melakukan penelitian dengan teman serumpun atau interdisiplin; memperbanyak menulis dan mempublikasikan artikel jurnal bereputasi; mengikuti konferensi; bertanya kepada lembaga puslitpen dan melakukan penelitian melibatkan mahasiswa. 
Pertanyaan yang kedua: Tulis saran bapak/ibu dalam rangka meningkatkan akselerasi publikasi hasil penelitian? diperoleh hasil sebagai berikut: Perbanyak program yang memfasilitasi publikasi bersama; memperbanyak forum penulisan coaching karya tulis; memperbnyak dana untuk publikasi minimal per dosen satu semester; membuat kelompok keahlian dalam atau luar institusi; fasilitasi dosen dalam mengakses jurnal internasional dan kemampuan bahasa inggris; Coaching kesulitan memahami template; mengadakan internasional conference; Tagihan outcome dan pemberian insentive yang disubsidi atau publish sendiri, konfrensi mandiri; dan sosialisasi laporan capaian publikasi pada sinta atau google scholar mempengaruhi dosen untuk meningkatkan publikasi hasil penelitian.

\section{KESIMPULAN}

Perguruan tinggi fokus pada upaya meningkatkan jumlah publikasi pada jurnal bereputasi nasional dan internasional. Khusus pada publikasi jurnal internasional terindeks scopus tiap perguruan tinggi mengembangkan strategi percepatan publikasi hasil penelitian yang dituangkan dalam bentuk rencana strategis PT atau rencana induk penelitian. PT melalui Wakil Rektor IV atau lembaga penelitian membuat lembaga yang fokus pada publikasi hasil penelitian yaitu lembaga jurnal dan publikasi.

Lembaga tersebut fokus pada outcome hasil penelitian membentuk: kolaborasi riset antar prodi, fakultas atau antar universitas, academic writing, pembentukan team TOT perguruan tinggi yang bertugas memberikan layanan klinik teknis penulisan jurnal internasional, coaching clinic, workshop artikel, dan dilaksanakannya internasional conference yang penyelenggaraanya didanani atau disubsidi oleh PT baik sebagai panitia penyelenggara atau sebagai mitra. Pimpinan PT sangat support terhadap upaya peningkatan percepatan publikasi hasil penelitian.

\section{Ucapan Terima Kasih}

Peneliti ucapkan terimakasih kepada kepala PuslitPen UIN Sunan Gunung Djati Bandung yang telah bersedia diwawancara dan atas izinnya peneliti dapat mengakses dokumen PuslitPen. Selanjutnya ucapan terima kasih kepada ketua tim Pengembang jurnal dan publikasi UPI atas izin pelaksanaan penelitian dan kepada Dr. Hj. Isma Widiaty, M.Pd. atas kesediaan waktunya untuk wawancara.

\section{KEPUSTAKAANACUAN}

Asep Bayu Dani Nandiyanto, Tuswadi, N. H. (2016) Menembus Publikasi Jurnal Internasional. 2nd edn. Bandung: Paramedia Komunikata.

Direktur Jenderal Pendidikan Islam (2015) 'Kementerian agama ri', in Petunjuk Teknis Perencanaan, Pelaksanaan, dan Pelaporan Penelitian, p. 2.

Ingrid van de Stadt, (2010), How to Write a Worldclass Paper, Regional Customer Development Manager, Elsevier.

LP2M, P. P. dan P. (2015a) Profil Pusat Penelitian dan Penerbitan.

LP2M, P. P. dan P. (2015b) Standar Operasional Prosedur.

LP2M, P. P. dan P. (2017) Panduan Pelaksanaan Penelitian dan Publikasi 2017. 
Lukman, D. (2016) Kekuatan 50 Institusi Ilmiah Indonesia. Jakarta: Direktorat Pengelolaan Kekayaan Intelektual Direktorat Jenderal Penguatan Riset dan Pengembangan Kementerian Riset, Teknologi, dan Pendidikan Tinggi.

Purwo Santoso (2010) Analisis Kebijakan Publik. Yogyakarta: Research Center for Politics and Government Jurusan Politik dan Pemerintahan Universitas Gadjah Mada.

Rencana Induk Penelitian UIN Sunan Gunung Djati (2015).
Ristek Dikti (2016) Kebijakan pengelolaan penelitian dan pengabdian kepada masyarakat di perguruan tinggi.

Sunarno (2009) 'Manajemen Publikasi Hasil Penelitian Pada Pusat Studi', Berkala Ilmu Perpustakaan dan Informasi, V(2), p. 18.

UPI (2015) Draf Rencana Strategis UPI 20162020.

Yohandri (2015) 'Strategi Mempublikasikan Hasil Penelitian dalam Jurnal Internasional Bereputasi', in Prosiding Seminar Nasional Pembelajaran Fisika II, p. 18. 